\title{
TEKNOLOGI 3D MAPPING DAN KONSEP KONTEKSTUAL PERANCANGAN MUSEUM EDUKASI SEKS DI MANGGA BESAR
}

\author{
Calvin Chandra ${ }^{1)}$, Lina Purnama ${ }^{2)}$ \\ 1) Program Studi S1 Arsitektur, Fakultas Teknik, Universitas Tarumanagara, calvin.chndr.cc@gmail.com \\ 2) Program Studi S1 Arsitektur, Fakultas Teknik, Universitas Tarumanagara, linapurnama.112@gmail.com
}

\begin{abstract}
Abstrak
Generasi milenial adalah generasi yang mahir menggunakan teknologi, mereka lahir ketika teknologi sudah ada di sekeliling mereka. Namun seiring perkembangan zaman terutama di bidang teknologi seperti penggunaan internet, gawai, dan perangkat komputer tentu juga membawa berbagai dampak negatif. Dengan mudahnya mengakses informasi, banyak dari generasi milenial sulit menyaring berbagai informasi yang ada saat ini, terutama konten-konten negatif seperti pornografi. Kelompok dengan frekuensi menggunakan internet yang tinggi (lebih dari empat jam) memiliki kecenderungan tinggi pula pada perilaku seksual pranikah (Indrijati,2017). Akibatnya saat ini, banyak dari generasi milenial terpapar oleh Penyakit Menular Seksual (PMS). Salah satu hambatan paling besar dalam pencegahan dan penanggulangan dari Penyakit Menular Seksual ini adalah karena kurangnya edukasi seks di Indonesia. Edukasi seks masih menjadi hal yang tabu untuk diperbincangkan dan disosialisasikan ke masyarakat umum. Hal inilah yang menyebabkan generasi milenial dengan sendirinya mencari informasi mengenai seks dan terpapar konten negatif seperti pornografi. Dengan menganalisis berbagai unsur edukasi seks sebagai dasar untuk mengedukasi dan memberikan informasi yang benar mengenai seks itu sendiri ke masyarakat luas, serta melihat perkembangan teknologi hiburan modern sebagai katalis pengenalan program, muncul ide untuk menggabungkan unsur edukasi seks dan teknologi hiburan modern tersebut dalam proyek museum. Teknologi 3D Mapping dimanfaatkan untuk memberi pengalaman baru dalam mengedukasi masyarakat. Tapak yang dipilih berada di daerah Mangga Besar sebagai kawasan yang terkenal sebagai "taman eden" pada malam hari karena terkenal sebagai pusat kuliner dan hiburan malam di Jakarta Barat. Proyek ini juga berinteraksi dengan sekitarnya sebagai tempat yang nyaman dengan ruang terbuka untuk masyarakat sekitar. Program didukung dengan ruang 3D Mapping, cafe, galeri, dan ruang seminar. Proyek ini diharapkan dapat mengubah persepsi masyarakat bahwa seks suatu topik yang tabu dan dapat mengedukasi masyarakat secara luas.
\end{abstract}

Kata kunci: 3D Mapping; Edukasi Seks; Mangga Besar; Museum; Ruang Terbuka

\begin{abstract}
Millennials is a generation that's gifted with techonology, they were born surrounded by technology. But as the time goes bye, using all the technologies such as mobile devices and internet would bring a negative effects. With all the easiness to access all information, many people (millennials) find it difficult to differentiate the negative and the positive ones, since the internet would provide all kind of information including the negatives such as pornography. A group of people who spent more time on the internet (more than four hours per-day) would have a higher tendency to premarital sexual behavior (Indrijati, 2017). As a result now, bunch of millennials are exposed to a sexually transmitted disease (STDs). Due to lack of sex education, preventing and controlling the disease has become a difficult task. Sex education still categorized as a 'taboo' thing to be discussed on public, even more to be educated. This becomes the main reason for many millennials to seek out the information by themselves through the internet, and eventually got exposed by the negative contents such as pornography. By analyzing various elements of sex education as the basis and providing a decent information that's suitable for the community especially
\end{abstract}


millennials, while also noticing modern entertainment's development as a catalyst to introduce the program. The idea is to emerge an incorporate elements of sex education and modern entertainment technology into a museum. 3d mapping technology used to provide a whole new experience on public education. The chosen site is on Mangga Besar area which known as the "Eden Garden" at night, because of the culinary center and the nightlife in West Jakarta. This project would also interacts with its surroundings, as an open space for the communities around. This project consisted of some programs which is, supported by 3d mapping room, café, gallery, and seminar room. This project aim to amend people's perception of sex as a taboo thing to become something that must be educated to all the community.

Keywords : 3D Mapping; Mangga Besar; Museum; Open Space; Sex Education

\section{PENDAhULUAN}

Teknologi menjadi hal yang sangat penting dan sudah menjadi kebutuhan dasar masyarakat kota metropolitan, salah satunya yaitu teknologi jaringan internet. Banyak hal yang dapat dilakukan hanya dengan mengandalkan koneksi jaringan internet, mulai dari media sosial atau jejaring sosial, mencari informasi, bahkan melakukan transaksi jual beli. Generasi milenial adalah generasi yang mahir menggunakan teknologi, mereka lahir ketika teknologi sudah ada di sekeliling mereka. Namun seiring perkembangan zaman terutama di bidang teknologi seperti penggunaan internet, gawai, dan perangkat komputer tentu juga membawa berbagai dampak negatif. Dengan mudahnya mengakses informasi, banyak dari generasi milenial sulit menyaring berbagai informasi yang ada saat ini, terutama konten-konten negatif seperti pornografi. Kelompok dengan frekuensi menggunakan internet yang tinggi (lebih dari empat jam) memiliki kecenderungan tinggi pula pada perilaku seksual pranikah (Indrijati,2017). Akibatnya saat ini, banyak dari generasi milenial terpapar oleh Penyakit Menular Seksual (PMS). Salah satu hambatan paling besar dalam pencegahan dan penanggulangan dari Penyakit Menular Seksual ini adalah karena kurangnya edukasi seks di Indonesia. Terlebih di Indonesia dengan adat ketimuran, seks jadi masalah tabu untuk diperbicangkan dan disosialisasikan ke masyarakat umum. Hal inilah yang menyebabkan generasi milenial dengan sendirinya mencari informasi mengenai seks dan terpapar konten negatif seperti pornografi.

Kentalnya stigma negatif yang melekat pada informasi seputar seks semakin membuat generasi milenial takut untuk bertanya. Edukasi seks penting untuk membantu generasi milenial dan generasi seterusnya untuk memahami resiko yang bisa ditimbulkan dari perilaku seksual pranikah. Dengan menganalisis berbagai unsur edukasi seks sebagai dasar untuk mengedukasi dan memberikan informasi yang benar mengenai seks itu sendiri ke masyarakat luas, serta melihat perkembangan teknologi hiburan modern sebagai katalis pengenalan program, muncul ide untuk menggabungkan unsur edukasi seks dan teknologi hiburan modern tersebut dalam proyek museum. Proyek ini juga berinteraksi dengan sekitarnya sebagai tempat yang nyaman dengan ruang terbuka untuk masyarakat sekitar. Program didukung dengan ruang 3D Mapping, kafe, galeri, dan ruang seminar. Proyek ini diharapkan dapat mengubah persepsi masyarakat bahwa seks suatu topik yang tabu dan dapat mengedukasi masyarakat secara luas.

\section{KAJIAN LITERATUR}

Milenial atau kadang disebut juga dengan Generasi $Y$ adalah sekelompok orang yang lahir setelah Generasi X, yaitu orang yang lahir pada kisaran tahun 1981 hingga 1994. Hal ini berarti milenial adalah generasi muda yang berumur 25-38 pada tahun ini. Generasi ini didahului oleh generasi Maturists, Baby Boomers, dan Generasi X, dan diikuti oleh Generasi Z. Masing masing memiliki karakteristik yang berbeda, akrena tumbuh di tengah kondisi yang berbeda. Milenial sendiri dianggap special karena generasi ini sangat berbeda dengan generasi 
sebelumnya, apalagi dalam hal yang berkaitan dengan teknologi. Generasi milenial memiliki ciri khas tersendiri, mereka lahir saat era TV berwarna, handphone juga internet sudah diperkenalkan. Tak heran jika generasi ini sangat mahir dalam penggunaan teknologi.

\section{Generasi milenial dalam konteks sejarah dan budaya}

Dilihat dari parakteknya, generasi milenial dinilai cenderung cuek pada keadaan sosial. Bahkan, teknologi juga dapat mengubah kebudayaan dengan cepat. Misalnya, pada umumnya manusia itu harus saling berinteraksi dan saling membutuhkan satu dengan lainnya. Namun, teknologi mampu mengubahnya dengan cepat. Dengan teknologi, generasi milenial cenderung terhadap individualis yang mengejar pola gaya hidup yang eksis di sosial media.

Kehadiran teknologi generasi milenial cenderung meninggalkan nilai-nilai budaya dan agama, mengejar nilai-nilai kebebasan, hedonisme, party dan pergaulan bebas. Ternyata apabila ditelusuri, bahwa generasi milenial tersebut banyak yang berdampak negatif pada dirinya sendiri juga. Dengan gaya hidup teknologi, nilai-nilai yang ditanamkan pada diri seorang anak akan hilang mengikuti arus generasi milenial.

Generasi milenial cenderung bersikap individualis yang mementingkan diri sendiri tanpa memikirkan orang lain. Generasi millennial berpengaruh terhadap kehidupan sosial, yang lebih mementingkan ego masing-masing sehingga sikap dan perilaku yang terjadi adalah menyimpang melakukan sesuatu sesuai dengan keinginan sendiri tanpa memikirkan sekitar.

\section{Edukasi Seks}

Pendidikan seks pada hakikatnya merupakan usaha untuk membekali pengetahuan tentang fungsi organ reproduksi dengan menanamkan moral, etika serta agama agar tidak terjad penyalahgunaan organ reproduksi tersebut. Pendidikan seks bisa dikatakan suatu pesan moral.

Pendidikan seks dapat dikatakan sebagai cikal bakal pendidikan kehidupan berkeluarga yang memiliki makna sangat penting. Bahkan para ahli psikologi menganjurkan agar anak-anak sejak dini hendaknya mulai dikenalkan dengan pendidikan seks yang sesuai dengan tahap perkembangan kedewasaan mereka. Pengertian ini menunjukan bahwa pendidikan seks sangatlah luas bukan hanya terkait dimensi fisik, namun juga psikis dan sosial. Meski demikian saat ini telah terjadi pereduksian makna. Pendidikan seks hanya disempitkan hanya pada aspek pembelajaran dalam hubungan seks saja. Akibatnya pendidikan seks menjadi tabu untuk bicarakan apalagi dipelajari. Pada akhirnya remaja mencari jalan untuk mencari informasi seks dari sumber-sumber lain seperti buku bacaan, gambar, dan film yang berbau pornografi.

\section{Tipologi Bangunan Museum}

Museum adalah lembaga yang diperuntukan bagi masyarakat umum.Museum berfungsi mengumpulkan, merawat, dan menyajikan serta melestarikan warisan budaya masyarakat untuk tujuan studi, penelitian dan kesenangan atau hiburan. (Ayo Kita Mengenal Museum : 2009). Definisi museum menurut Association of Museum yaitu "Museum merupakan sebuah badan yang mengumpulkan, mendokumentasikan, melindungi, memamerkan dan menunjukkan materi bukti dan memberikan informasi demi kepentingan umum." Secara Etimologi kata museum berasal dari bahasa latin yaitu "museum" ("musea"). Aslinya dari bahasa Yunani mouseion yang merupakan kuil yang dipersembahkan untuk Muses (dewa seni dalam mitologi Yunani), dan merupakan bangunan tempat pendidikan dan kesenian, khususnya institut untuk filosofi dan penelitian pada perpustakaan di Alexandria yang didirikan oleh Ptolomy I Soter 280 SM.

Berdasarkan Peraturan Pemerintah RI No. 19 Tahun 1995, museum adalah lembaga, tempat penyimpanan, perawatan, pengamanan dan pemanfaatan benda-benda bukti materiil hasil budaya manusia serta alam dan lingkungannya guna menunjang upaya perlindungan dan pelestarian kekayaan budaya bangsa. Sedangkan menurut International Council of Museum (ICOM) : dalam Pedoman Museum Indonesia, 2008. Museum adalah sebuah lembaga yang bersifat tetap, tidak mencari keuntungan, melayani masyarakat dan perkembangannya, 
terbuka untuk umum, memperoleh, merawat, menghubungkan dan memamerkan artefakartefak perihal jati diri manusia dan lingkungannya untuk tujuan studi, pendidikan dan rekreasi.
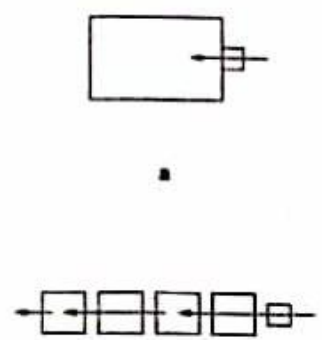

c

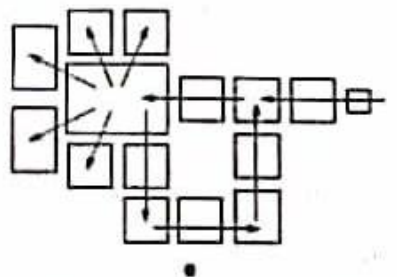

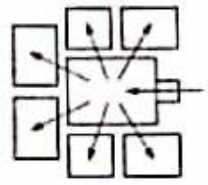

b
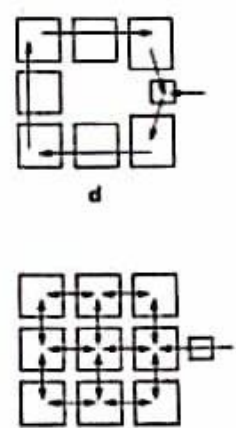

28.7 Genetic plans for exhibit and open-access storage areas:

a Open plan; b Core + satellites; c Linear procession; d Loop:

e Complex; r Labyrinth

\section{Gambar 1. Alur Sirkulasi Museum}

Sumber: Atler, 1969

Museum mengumpulkan dan merawat benda-benda ilmu pengetahuan alam, benda-benda seni, dan benda-benda yang memiliki sejarah penting agar tampak bernilai dan dipamerkan kepada masyarakat umum melalui pameran permanen dan temporer. Museum besar terletak di kota besar dan museum lokal berada di kota kecil. Kebanyakan museum menawarkan program dan kegiatan yang menjangkau seluruh pengunjung, termasuk orang dewasa, anakanak, seluruk keluarga, dan tingkat profesi lainnya. Kedudukan museum di Indonesia sekarang dibawah Departemen Pendidikan dan Kebudayaan, yang artinya secara tidak langsung dikelola oleh pihak pemerintah.

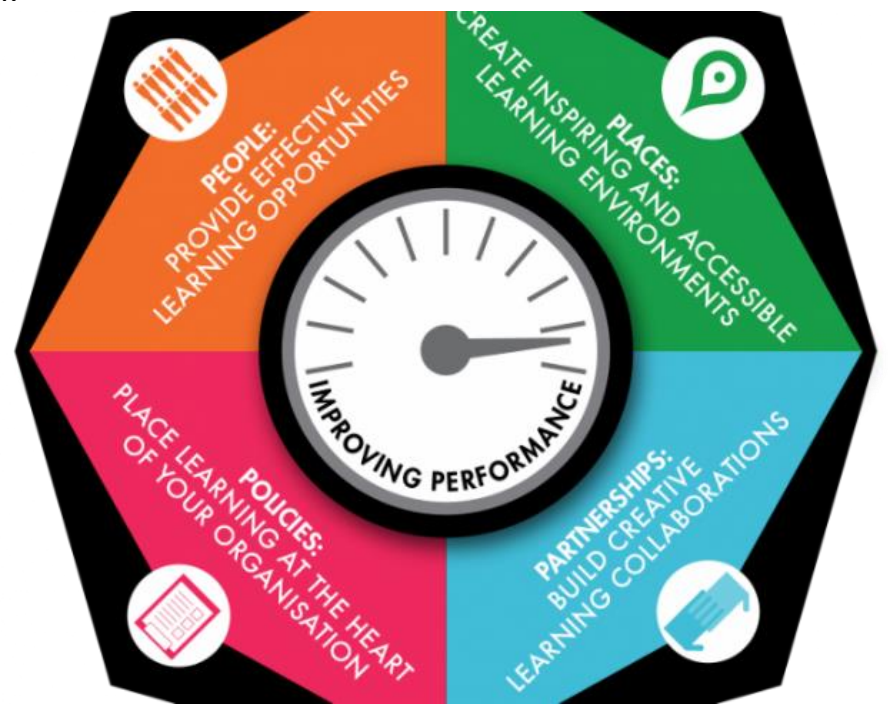

Gambar 2. Kerangka berpikir MLA Inspiring Learning Sumber: http://www.artscouncil.org.uk/ 
Fungsi dasar dari sebuah Museum adalah mengkoleksi dan memelihara obyek-obyek dan spesimen-spesimen serta memamerkannya secara teratur kepada khalayak ramai. Museum juga memberikan program inovasi dan pameran.

Gertrud Rudolf Hidle menjelaskan bahwa museum adalah tempat yang berfungsi mengumpulkan barang -barang warisan kebudayaan bagi kepentingan ilmu pengetahuan dan segalah hubungannya harus di pamerkan kepada umum. Jika di lihat dari desain museum itu sendiri mengalami banyak perkembangan sesuai jamannya. Sebagai contoh museum jaman romawi dan yunani kuno biasanya memiliki desain sederhana namun raksasa. Sedang bangunan museum pada zaman modern memiliki bentuk yang kompleks dan abstrak.

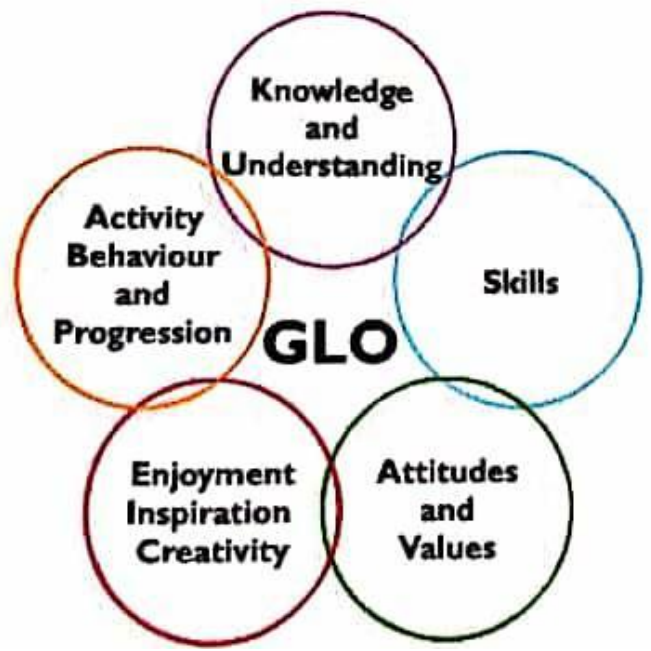

Gambar 3. Diagram Generic Learning Outcomes

Sumber: http://www.artscouncil.org.uk/

\section{METODE}

Metode perancangan yang digunakan dalam perancangan ini :

a. Studi Literatur

- Sebagai dasar teoritis untuk dasar konsep pemikiran

- Mengetahui urban fabric yang membangun kota

- Mengetahui standar yang terkait perancangan ruang kota

b. Studi preseden

- Sebagai pembanding antara proyek.

- Mengerti standar yang dipakai proyek yang dijadikan sebagai preseden.

c. Pengamatan lingkungan

- Lokasi: a) lokasi sekitar kawasan THR lokasari , b) Jalan Mangga Besar Raya

- Waktu: Siang hingga malam hari, Pukul 14:00 - 21:00

d. Metode pengamatan: a) Survey lapangan, b) Pengambilan foto

\section{DISKUSI DAN HASIL}

\section{Program}

Program didasarkan kepada visi utama proyek yaitu menjadi 'wadah' dan 'wajah' baru untuk mengedukasi masyarakat mengenai seks. Dengan mewadahi, menjadi tempat aktivitas masyarakat untuk berinteraksi satu sama lain dan belajar melalui media galeri dan ruang $3 D$ mapping yang berisikan perangkat proyektor dan audio. Sebagai 'wajah', bangunan menjadi wajah baru yang mengubah persepi masyarakat mengenai seks itu sendiri.

Pengadaan acara terkait di tingkat lokal dapat dinikmati berbagai kalangan dilakukan di ruang terbuka, yang dapat digunakan pula sebagai tambahan ruang bagi pengunjung sekitar Mangga Besar khususnya keluarga dan anak-anak. Program yang bersifat publik ini melihat sifat pengunjung yang nantinya akan mendatangi museum berbeda beda, terbagi atas kategori 
umur yaitu: anak-anak, remaja, dan orang dewasa. Dalam kategori jumlah: grup, keluarga, dan individual. Sehingga program terbagi atas program utama yaitu ruang $3 D$ mappping, galeri, ruang seminar, dan perpustakaan, serta program penunjang yang dapat digunakan sebagai fasilitas bagi linkungannya yaitu restoran, kafe, dan ruang terbuka yang sifatnya publik.

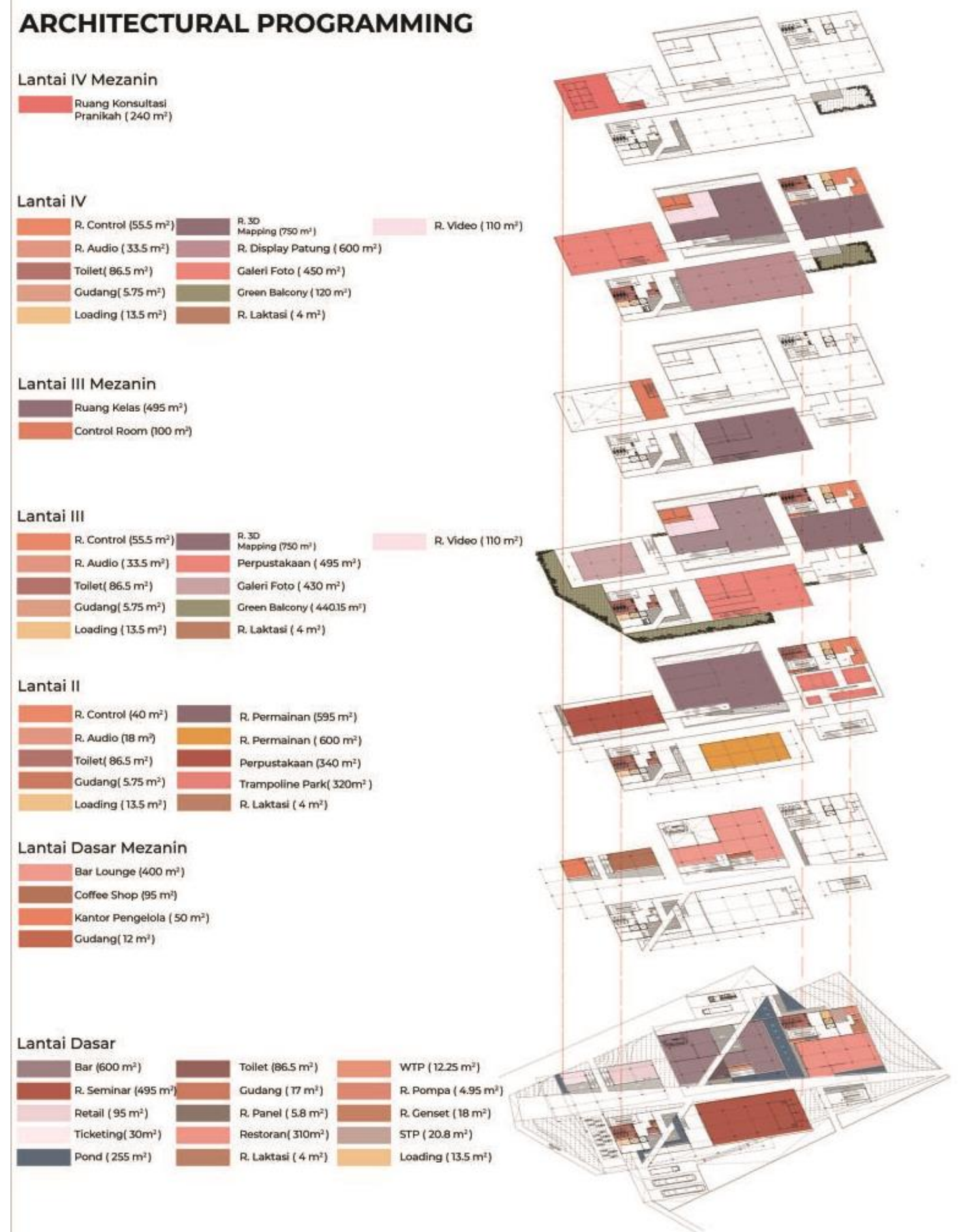

Gambar 4. Luasan Program Utama dan Fasilitas Sumber: Penulis, 2019 


\section{Tapak}

MAPPING LINGKUNGAN
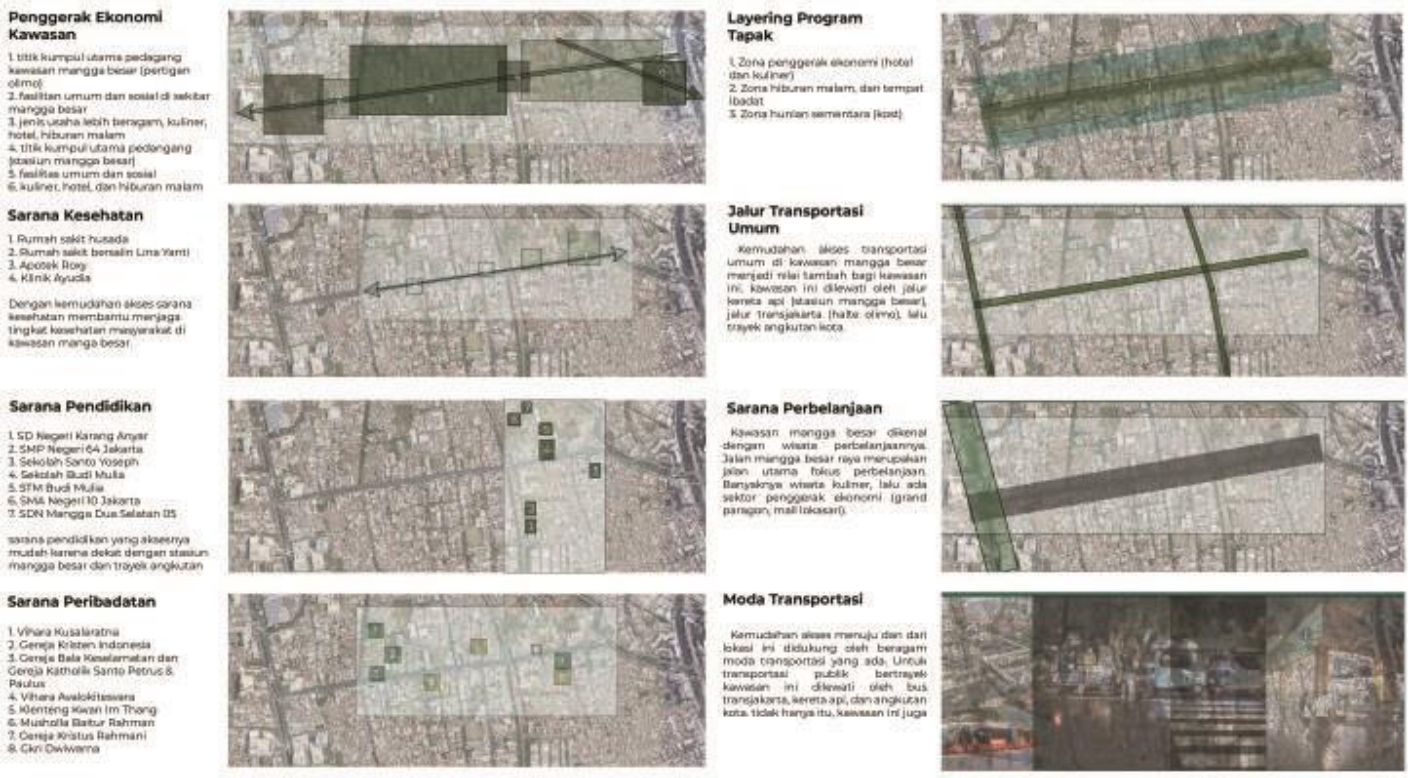

Gambar 5. Posisi Tapak Terhadap Sekitar

Sumber: Penulis, 2019

Tapak terpilih berada di Jalan Mangga Besar 13, di kawasan Mangga Besar. Tapak ini dipilih karena memenuhi kriteria tapak yaitu: merupakan kawasan aktif yang memiliki konteks prostitusi yang kuat, mudah diakses menggunakan transportasi umum, dan dekat dengan sarana pendidikan (sekolah) sebagai sasaran utama, dan merupakan lahan yang tidak aktif atau tidak terbangun.

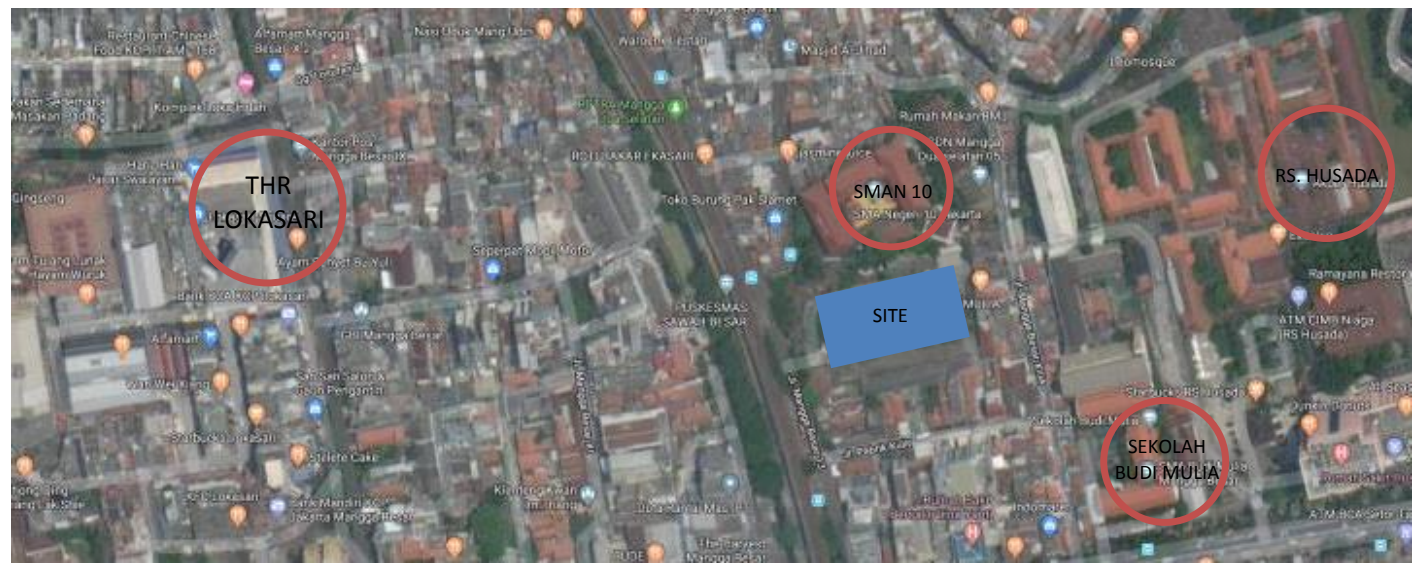

Gambar 6. Posisi Tapak Terhadap Sekitar

Sumber: Google Maps, 2019

Tapak berbatasan langsung dengan Rumah Sakit Husada pada bagian timur, sehingga usulan program dinilai cocok untuk mensosialisasikan dari bahayanya perilaku seks pranikah. Pada bagian utara dan selatan tapak berbatasan langsung dengan sekolah SMAN 10 dan Yayasan Budi Mulia yang dinilai cocok dengan konteks sebagai media edukasi bagi amsyarakat luas, sementara pada bagian Barat Laut menghadap langsung dengan THR Lokasari sebagai pusat prostitusi di kawasan Mangga Besar. Terdapat aksis yang kuat dan saling bersinggungan, yaitu aksis THR Lokasari - Tapak dan aksis Tapak dengan Rumah Sakit Husada. Sementara di tengah pertemuan aksis tersebut diapit oleh sekolah SMAN 10 dan Budi Mulia sehingga memungkinkan visualitas dan akses yang menghubungkan bangunan itu. 


\section{Konsep}

Terletak di kawasan dengan identitas khas Mangga Besar, bentuk dan wujud bangunan kontekstual terhadap tapak dan sekitarnya. Berawal dari bentuk tapak yang memanjang ke belakang, menghadap jalan Mangga Besar 13, dan membelakangi jalan mangga Besar 13 Dalam. Pertimbangan massa, dilanjutkan dengan pembuatan jalur tembus terhadap sekitarnya dan orientasi massa yang diputar menghadap THR Lokasari (lihat gambar 6). Lantai dasar dibuat terbuka untuk publik sebagai tempat untuk berinteraksi dan beristirahat sejenak dari kesibukan sehari-hari.

Tabel 1. Besaran Luas Proyek dan Data Tapak

\begin{tabular}{ccc}
\hline & Desain Program & Ketentuan \\
\hline KDB (Koefisien Dasar Bangunan) & $3.982 \mathrm{~m}^{2}$ & $4.119 \mathrm{~m}^{2}(60 \%)$ \\
\hline KTB (Koefisien Tapak Basement) & - & - \\
\hline KLB (Koefisien Luas Bangunan) & $16.250 \mathrm{~m}^{2}$ & $16.478 \mathrm{~m}^{2}(2.4)$ \\
\hline KDH (Koefisien Dasar Hijau) & $2.197 \mathrm{~m}^{2}$ & $2.059 \mathrm{~m}^{2}(30 \%)$ \\
\hline Total Luas Bangunan & & \\
\hline
\end{tabular}

Sumber: Penulis, 2019

Selanjutnya pembentukan bidang tangkap dengan memotong massa menjadi dua bagian untuk menciptakan plaza dan akses masuk pengunjung dan orientasi terhadap jalan utama dengan menghadap jalan Mangga Besar 13 (lihat gambar 7). Kedua massa bangunan itu kemudian dihubungkan oleh jembatan untuk menarik pengalaman ruang luar dan ruang dalam agar lebih menyatu. Ruang-ruang hijau hijau diciptakan berupaya menjadi katalisator hijau di kawasan Mangga Besar yang sudah padat dan kurangnya ruang terbuka (lihat gambar 7).

\section{DESIGN SCHEME}

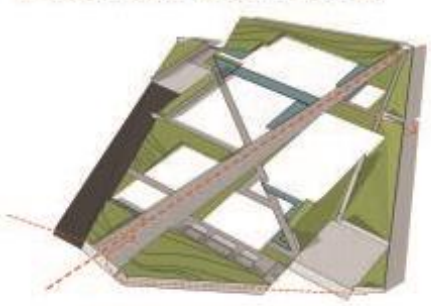

PEDESTRIAN FLOW AXIS Menciptakan tempat komunal
dengan mengutamakan pedestrian dengan mengutamakan pedestrian dan meneruskannnya ke seklar dan mak.

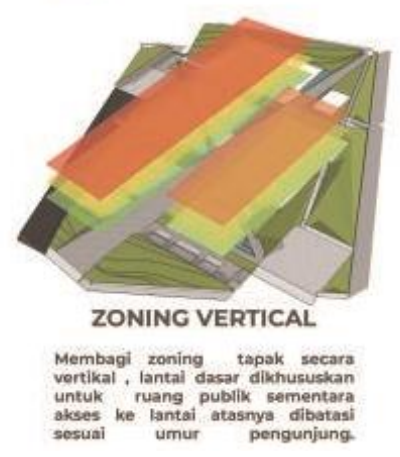

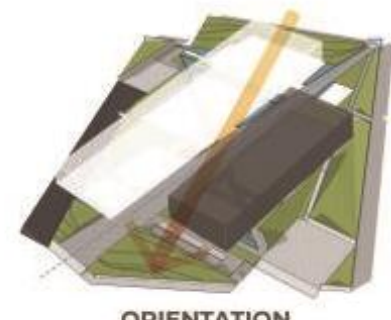

ORIENTATION

Memutar massa bangunan berupaya menghindari orientasi matahar socara

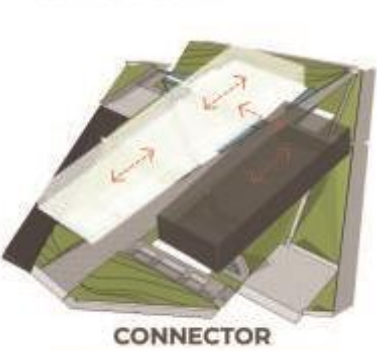

Penghubung antas massa bangunan disolingi oleh landscpao tapak bertujuan untuk menarik
pengalaman ruang luar dan ruang
dalam agar lebih menyatu.

Gambar 7. Proses Gubahan Massa

Sumber: Penulis, 2019

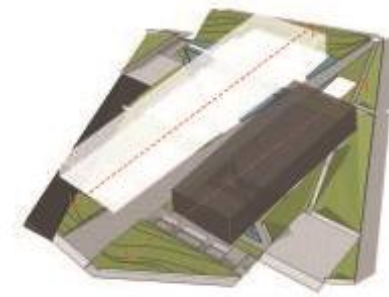

MASS PLACEMENT Massa bangunan menyesuaikan bentuk geometri tapak yang kista

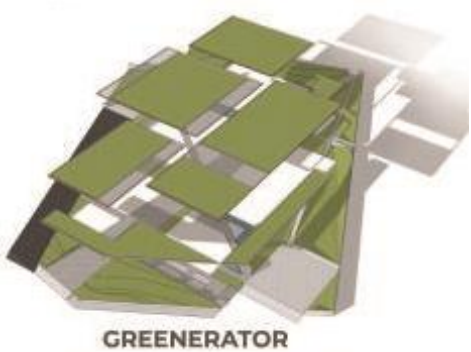

GREENERATOR

Ruang - ruang hijau yang hadir borupaya monjal pomicu kawasan of kawasan Mangga besar. 


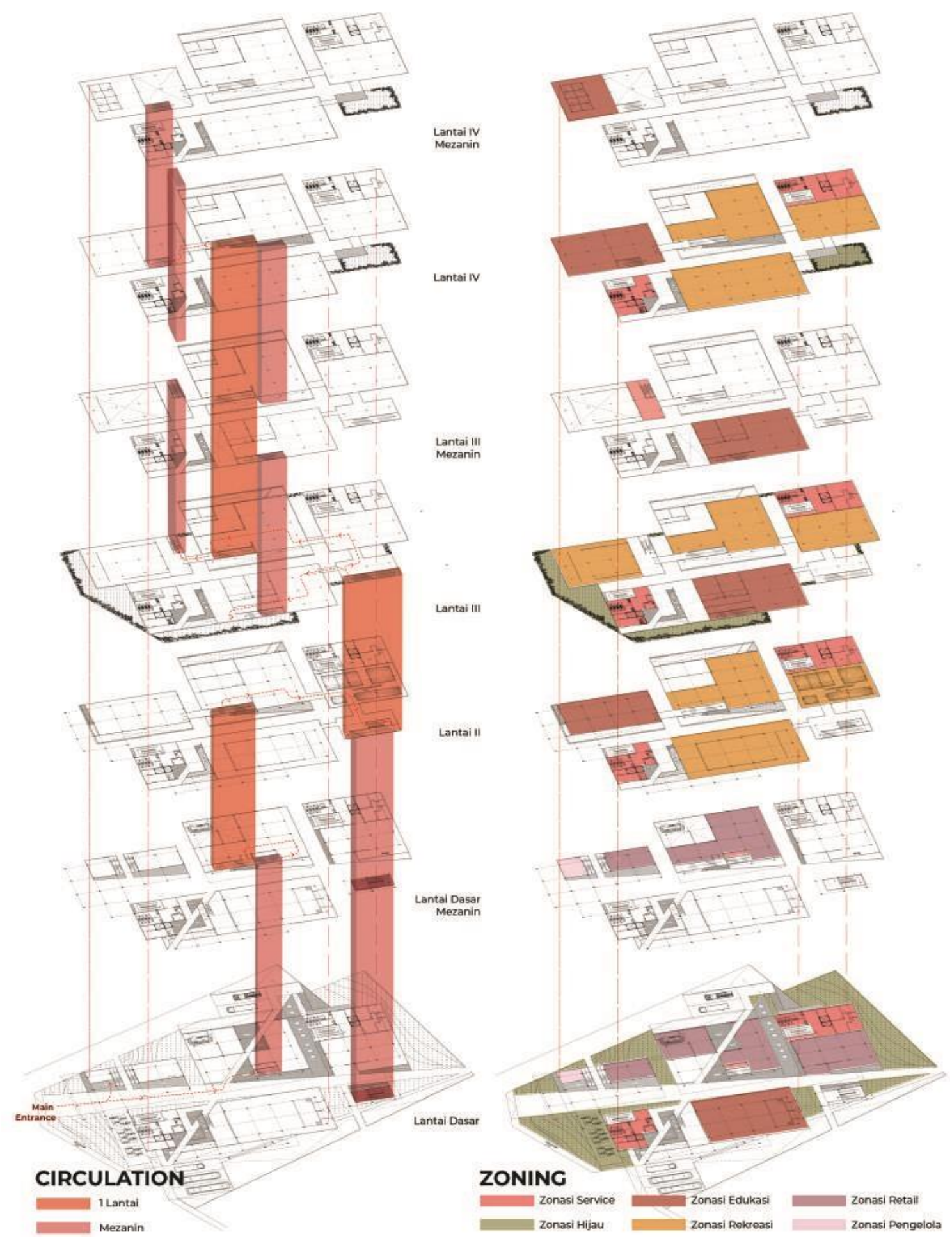

Gambar 8. Konsep Sirkulasi dan Pembagian Zoning Vertikal - Horizontal Sumber: Penulis, 2019 


\section{KESIMPULAN DAN SARAN}

Untuk mengedukasi seks lebih luas kepada masyarakat membutuhkan media yang lebih interaktif dan tidak melulu secara formal, yang kemudian dipersempit yaitu, media interaktif sebagai tema. Kurangnya edukasi seks dan pandangan negatif masyarakat mengenai isu ini, serta kebutuhan perkembangan teknologi sebagai media edukasi melahirkan obyek wisata sekaligus sarana edukasi baru yang menghubungkan keduanya melalui bangunan dan program proyek. Konsep campuran antara edukasi dan media interaktif, digunakan pada program utama, tempat pengunjung merasakan pengalaman belajar sekaligus bermain dengan fitur seperti videogame, dan ruang 3D Mapping yang sedang berkembang menjadi program yang baru, serta konsep kontekstual pada bangunan, membuat keserasian dengan lingkungan namun memberikan pengalaman unik bagi pengunjung museum. Proyek diharapkan menjadi gebrakan baru dan dapat mengubah persepsi masyarakat mengenai seks yang selama ini selalu tabu untuk diperbincangkan, menjadi tempat wisata hiburan modern yang relevan untuk masa yang akan datang.

\section{BIBLIOGRAFI}

Antoniades, C, A. (1992). Poetics of Architecture : Theory of Design. New York: Van Nostrand Reinhold.

Atler, D. (1969). Metric Handbook Planing and Design Data

Eilean, H. G. (1994). The Educational Role of the Museum 2nd edition. London: Routledge.

Gallup. (2016). How Millennials Want to Work and Live. Retrieved February 20, 2019, from https://www.gallup.com/workplace/238073/millennials-work-live.aspx

Henderson, J. (1998). Museum Architecture. London: Mitchell Beazley.

Indrijati, H. (2017). Penggunaan Internet dan Perilaku Seksual Pranikah Remaja.

Utomo, W.P. (2019). Indonesia Millennial Report [Electronic version]. Jakarta: IDN Research Institute.

Wulantika, S (2014). Pentingnya Mengenalkan Pendidikan Seks Sejak Usia Dini, Kompasiana, diunduh 20 Februari 2019, https://www.kompasiana.com/wicka14/54f8417ca33311855e8b48f6/pentingnyamengenalkan-pendidikan-seks-sejak-usia-dini 